\title{
The predictive role of life goals and self determination traits on academic performance in a Romanian STEMM and non-STEM undergraduate cohort
}

\author{
ESZTER ENIKŐ MARSCHALKO ${ }^{1}$
}

KINGA KÁLCZA-JÁNOSI ${ }^{2}$

\begin{abstract}
Objective: Based on self-determination theory (SDT) and the importance of intrinsic motivation and self-determination in academic performance we investigated the predictive role of intrinsic and extrinsic life goals (aspirations) and self-determination traits (perceived control, self-awareness) in undergraduate academic performance. We analyzed the predictive role of the above in STEMM (Science, Technology, Engineering, Mathematics, and Medicine), respectively non-STEMM/ non-STEM (Humanities, Arts, Literature, and Management) fields of study, taking into account the literature which indicates the differing demands of each field.
\end{abstract}

Design: A cross-sectional, correlational study design was used, the survey was conducted online.

Participants: The sample consisted of 105 eligible undergraduate volunteers. The participants were divided into two groups: STEMM group with 39 undergraduates and non-STEM / non-STEMM group with 66 undergraduates.

Measures: Aspiration Index and Self-Determination Scale were applied and we gathered objective performance criteria data derived from high-school records (Baccalaureate Average, Average Grade / SAT, and ACT equivalent) and from current educational outcome assessments of students (weighted Grade Point Average).

Methods: hierarchical multiple regression analyses were performed to examine statistically significant predictors and the predictive power of the proposed models.

Results: The findings highlighted a complex situation on academic performance predictors, with some paradoxical elements in it. Self-awareness seems not to count. The perceived choice was a significant negative predictor indicating that participants with higher perceived choice have lower academic performanceand

${ }^{1}$ Babes-Bolyai University, Faculty of Psychology and Education Science, Department of Applied Psychology, Cluj-Napoca, Romania, E-mail address: eszter.marschalko@ubbcluj.ro, corresponding author

${ }^{2}$ Babes-Bolyai University, Faculty of Psychology and Education Science, Department of Applied Psychology, Cluj-Napoca, Romania 
fame was a positive predictor of academic performance in non-STEM fields. Study field related diversity in prediction role is presented.

Discussion: Findings are discussed in the context of cultural moderation, genderspecific patterns, identity development, and financial background influence. Possible culturally mediated socio-cognitive components a re assumed and crosscultural further research is suggested.

\section{Keywords}

academic performance, life goals, self-determination, perceived choice, selfawareness, STEMM, STEM, non-STEM, undergraduate 